CLINICAL STUDY

\title{
Increasing use of radioiodine in young people with thyrotoxicosis in Great Britain
}

\author{
Neil Turner, Ian Driver, Jane A Salotti ${ }^{1}$, Mark S Pearce ${ }^{1}$ and Tim Cheetham ${ }^{2,3}$ \\ Nuclear Medicine, Regional Medical Physics Department, Freeman Hospital, Newcastle-upon-Tyne NE7 7DN, UK, ${ }^{1}$ Institute of Health and Society, \\ Newcastle University, Sir James Spence Institute, Royal Victoria Infirmary, Newcastle-upon-Tyne NE1 4LP, UK, ${ }^{2}$ Institute of Genetic Medicine, \\ Newcastle University, Central Parkway, Newcastle-upon-Tyne NE1 3BZ, UK and ${ }^{3}$ Department of Paediatric Endocrinology, c/o Old Children's Out \\ Patients, Royal Victoria Infirmary, Newcastle-upon-Tyne NE1 4LP, UK
}

(Correspondence should be addressed to T Cheetham at Department of Paediatric Endocrinology, clo Old Children's Out Patients, Royal Victoria Infirmary; Email: tim.cheetham@nuth.nhs.uk)

\begin{abstract}
Objective: Radioiodine (RI) is an important therapeutic option in young patients with thyrotoxicosis. We wanted to determine whether RI is being used more frequently in this age group. Design: National survey of Great Britain (England, Wales and Scotland).

Methods: Sixty-one medical physics departments were asked to provide the age and number of patients with thyrotoxicosis $<21$ years treated with RI (1990-2008). Information on the total number of RI treatments for thyrotoxicosis was also collected.

Results: Forty-three departments (70\%), with representation from 21 of the 25 most populous areas of Great Britain, provided data on 69258 treatments. The number of treatments recorded on patients $<21$ years during this period was $560(0.9 \%)$. The frequency of treatments in young people as a percentage of the total increased from $0.2 \%$ in 1990 to $1.5 \%$ in $2008(P<0.001)$. When the 18 centres submitting at least 17 years of data were analysed, a similar pattern was observed. The maximum number of young people treated was greatest in 2008 (62) with a fall in the youngest age at which RI was administered from 18 years (1990) to 11 years (2008).

Conclusions: A rising proportion of patients with thyrotoxicosis receiving RI are in those $<21$ years. This is largely due to an increase in the number of young people treated with a reduction in the minimum age at RI administration. We suspect that European clinicians are becoming more comfortable with RI treatment in young people with thyrotoxicosis, although a changing incidence is a potential contributing factor.
\end{abstract}

European Journal of Endocrinology 167 715-718

\section{Introduction}

Radioiodine (RI) has an important and well-established role in the treatment of thyroid cancer in the young. However, it is increasingly being promoted as a safe and cost-effective way of treating benign thyroid disease in young people as well. Data from Europe and North America have shown that short-term side effects such as thyroid storm are uncommon following RI administration in patients with thyrotoxicosis and the low additional radiation exposure during therapy has not resulted in a measurable overall increase in long-term neoplasia, or other adverse effects, to date $(1,2)$. This information is of considerable potential value to paediatric endocrinologists because a 2 - to 4 -year course of anti-thyroid drugs will only result in remission in a minority of patients $(2,3)$. Although anecdotal evidence suggests that some paediatric endocrinologists in the UK now consider RI to be a safe and effective alternative to surgery in young patients with thyrotoxicosis, there is as yet no formal strategy in Great Britain to collect longerterm data on RI usage in the young or to study any potential long-term consequences of these exposures on health. We therefore set out to survey RI usage in the young in Great Britain (England, Scotland and Wales) to determine whether there was evidence of a change in the pattern of RI prescribing in this age group.

\section{Materials and methods}

This was a survey of practice with no identifiable patient data and hence formal research ethics committee approval was not required. Sixty-one Medical Physics Departments in Great Britain were approached by letter and then by a phone call, if there was no response. Those administering RI to the young were provided with a questionnaire to complete and return in which they were asked to provide details of yearly RI administration to patients with thyrotoxicosis under the age of 21 years 


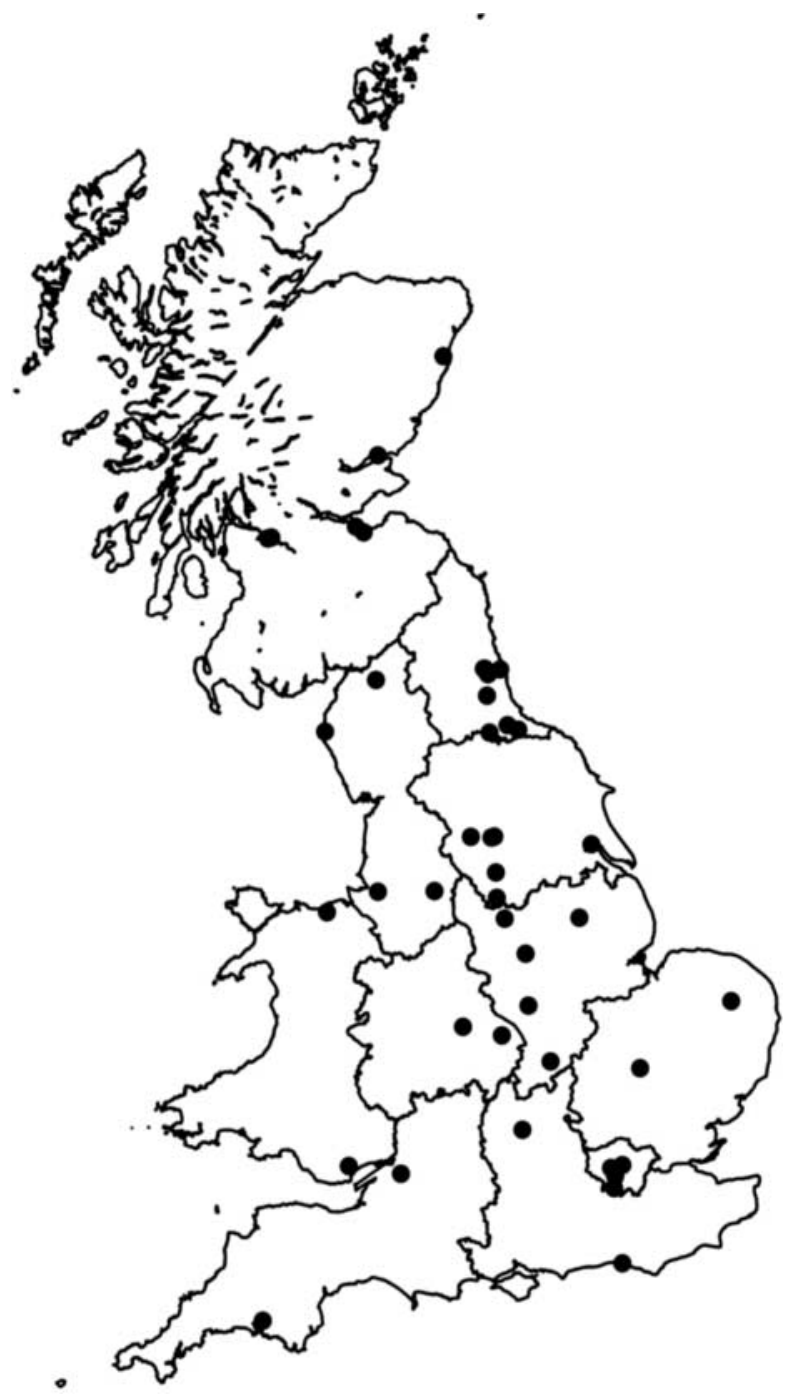

Figure 1 Map of Great Britain showing the centres submitting data as part of the survey.

during the 19-year period from 1990 to 2008. They were also asked to provide details of the total number of RI treatments for thyrotoxicosis to allow an assessment of whether the rates of administration in young people had changed over time as a percentage of overall RI usage. We suspected that it was the larger centres in the most populated areas where most RI administration would occur because they contain the majority of Great Britain's tertiary paediatric and adult endocrine departments.

We therefore tried to ensure that these centres were represented in our survey. We were aware that data from the earlier years of the survey would not be as readily available and, as part of an additional analysis, elected to analyse data from centres returning information for at least the last 17 of the 19-year study period $(\sim 90 \%$ or more of the years in question) in addition to the analysis performed on all collected data.
These data were analysed by determining the correlation between year of RI administration and the percentage of RI treatments administered to young people as well as the age of the youngest person treated.

\section{Results}

Of the 61 departments contacted, $43(70 \%)$ provided data. Figure 1 shows the location of the departments who submitted data. The majority (21 out of 25 ) of the most populated areas of Great Britain according to the 2001 census were represented in these 43 centres (http://www.ons.gov.uk/ons/rel/census/census-2001key-statistics/urban-areas-in-england-and-wales/index. html; http://www.gro-scotland.gov.uk accessed June 2012). The survey commenced in 2009 and finished in 2011. The time taken to conduct the survey reflects the amount of time taken for units to respond or supply data. The reasons for units not providing data included failing to respond to correspondence or not actually administering RI treatment (the major reasons) as well as not being in a position to submit data (due to lack of resources), not having an accessible record or, finally, agreeing to submit information but then failing to do so.

There was a steady increase in the total number of treatments in the included departments during the period of the audit - from 1099 in 1990 up to a peak of 4854 in 2005 . The total number of treatments fell in many of the 43 departments towards the end of the period of the survey with a $13 \%$ fall from the peak in 2005 down to a total of 4235 treatments in 2008. The 1099 treatments recorded in 1990 and 4235

Table 1 Overall use of RI compared with administration in patients under 21 years old.

\begin{tabular}{|c|c|c|c|c|}
\hline Year & $\begin{array}{l}\text { Total no. of } \\
\text { treatments } \\
\text { per annum }\end{array}$ & $\begin{array}{l}\text { Total no. of } \\
\text { treatments } \\
\text { in patients } \\
<21 \text { years }\end{array}$ & $\begin{array}{c}\text { Patients } \\
<21 \text { years } \\
(\%)\end{array}$ & $\begin{array}{c}\text { No. of units } \\
\text { submitting } \\
\text { data on } \\
\text { patients } \\
<21 \text { years }\end{array}$ \\
\hline 1990 & 1099 & 2 & 0.2 & 11 \\
\hline 1991 & 1562 & 7 & 0.4 & 13 \\
\hline 1992 & 2010 & 12 & 0.6 & 16 \\
\hline 1993 & 2323 & 16 & 0.7 & 17 \\
\hline 1994 & 2936 & 18 & 0.6 & 20 \\
\hline 1995 & 3168 & 14 & 0.4 & 20 \\
\hline 1996 & 3579 & 12 & 0.3 & 23 \\
\hline 1997 & 4103 & 27 & 0.7 & 28 \\
\hline 1998 & 4179 & 30 & 0.7 & 31 \\
\hline 1999 & 4257 & 34 & 0.8 & 31 \\
\hline 2000 & 4080 & 37 & 0.9 & 33 \\
\hline 2001 & 4324 & 40 & 0.9 & 33 \\
\hline 2002 & 4372 & 40 & 0.9 & 34 \\
\hline 2003 & 4345 & 40 & 0.9 & 35 \\
\hline 2004 & 4619 & 39 & 0.8 & 38 \\
\hline 2005 & 4854 & 36 & 0.7 & 39 \\
\hline 2006 & 4657 & 50 & 1.0 & 41 \\
\hline 2007 & 4556 & 44 & 1.0 & 42 \\
\hline 2008 & 4235 & 62 & 1.5 & 41 \\
\hline Total & 69258 & 560 & & \\
\hline
\end{tabular}




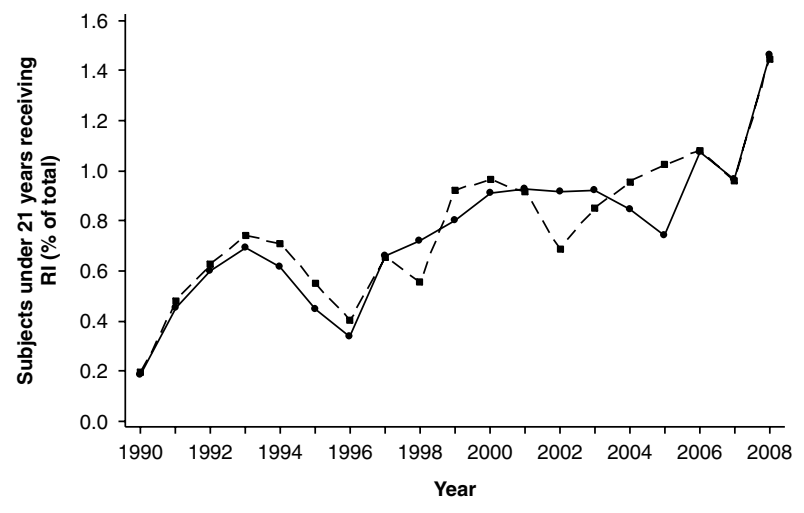

Figure 2 The number of treatments recorded on patients under 21 years during the study period (1990-2008) as a percentage of the total (continuous line) and the same percentage data in the 18 centres submitting at least 17 years of data (broken line).

treatments recorded in 2008 represent an overall 3.8-fold increase.

The number of treatments recorded on patients under 21 years during the period of study was $560(0.8 \%$ of total). The number of young patients receiving RI treatment as a percentage of the total rose approximately sevenfold over the 19-year study period from $0.2 \%$ in 1990 to $1.5 \%$ in $2008(r=+0.845, P<0.001$; Table 1, Fig. 2). The median age and youngest age at which RI was administered in young people under the age of 21 years was 20 and 19 years respectively in 1990 and 18 and 11 years respectively in 2008 ( $r=-0.794, P<0.001$; Fig. 3).

When the 18 departments submitting at least 17 years' data were analysed separately (40 949 treatments in total with 321 administered to young people under the age of 21 years), a similar increase from $0.2 \%$ in 1990 to $1.4 \%$ in 2008 was observed $(r=+0.837$, $P<0.001$; Fig. 2). There were no missing data for these 15 centres between 1997, when $0.7 \%$ of patients treated with RI were under 21 years, and 2008 by which time the figure had risen to $1.4 \%$.

\section{Discussion}

There are reports of RI administration to young people with thyrotoxicosis in the UK (4) and our survey suggests that this treatment modality is becoming more popular. The apparent increase in RI administration to the young has occurred at a time when reports from North America document the efficacy and safety of this treatment modality in this age group $(1,2)$. RI has previously appeared to be a more popular means of treating adults with benign thyroid disease in America when compared with Europe $(5,6,7)$. Our data may therefore reflect the fact that health professionals involved in the care of young people with thyrotoxicosis in Great Britain are becoming more comfortable with RI therapy. This is reflected in the steady fall in the age at which RI was administered. The fall in age at administration suggests that it is not just adult endocrinologists who are using RI more in the young but also paediatric endocrinologists.

We know that the incidence of acquired thyrotoxicosis is 0.9 per 100000 among $<15$ years olds in the UK and Ireland (8), but there is little information regarding changes in the incidence of thyrotoxicosis in children and adolescents. However, a twofold increase in incidence over a 10-year period up until 1998 was reported from Hong Kong (9). We expect that virtually all treated patients had autoimmune thyroid disease with most affected by Graves' disease rather than 'Hashitoxicosis' (10). The increase in RI treatments and the increase as a percentage of the overall total (children and adults) may therefore reflect the fact that autoimmune thyroid disease is becoming more common in young people. We suspect that this is a relatively minor factor because of the magnitude of the increase and because of the reduction with time in the age of the youngest patient treated. Most young people do not require more than one RI dose (2) and so multiple administrations to the same patient are unlikely to explain the observed trends.

Thyroid cancer is an uncommon disease in the young $(11,12)$ but is a well-recognised indication for RI therapy. However, we were careful to stipulate 'RI therapy for thyrotoxicosis' on the circulated questionnaire and so we do not think that the inclusion of RI therapy for other indications is likely to be a major confounding factor.

It is interesting to note the reduction in overall RI administration in the latter years of the survey. The reasons for this are unclear, but recent changes in the prevalence of autoimmune thyroid disease or a change in adult endocrine practice with greater use of antithyroid drug or surgery are possible explanations.

A significant limitation of our survey is the fact that we do not have representation from all hospitals in Great Britain and so we cannot be absolutely certain that the trends we have observed apply to all centres. However,

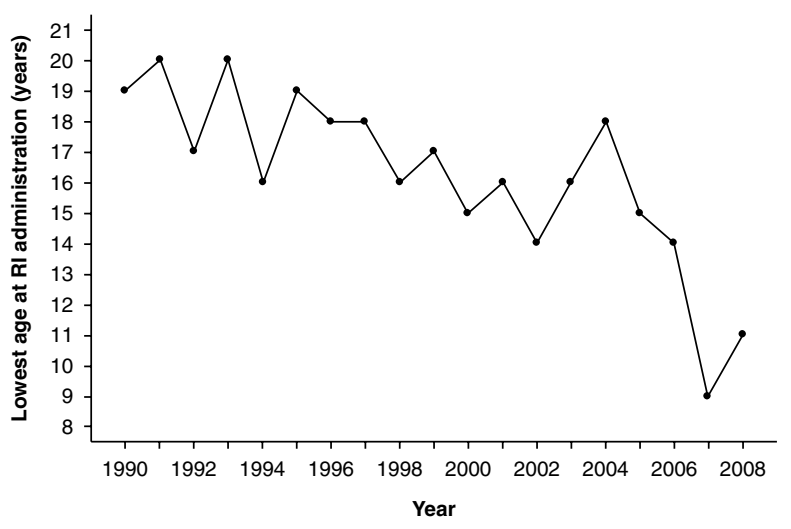

Figure 3 The age of the youngest patient administered RI for thyrotoxicosis by year. 
most of the major conurbations were represented in the data collected, and we believe that we have obtained data from enough centres for our observations to be relevant. The relative dearth of data in the earlier years of the audit is, according to discussions with the departments involved, primarily a reflection of inadequate records rather than units not having the facilities to administer RI. Importantly, the changing pattern of RI administration was still seen when departments submitting smaller amounts of data were excluded.

In summary, the proportion of young people receiving RI in Great Britain as a percentage of the total is increasing. The absolute number of young people receiving RI therapy appears to be increasing as well. This may reflect factors such as an increase in the number of young people with autoimmune thyroid disease (9) or the fact that physicians are now using RI more frequently in the young patient with thyrotoxicosis. There is a strong argument for the implementation of a more formal mechanism for collecting data on RI administration in young people with benign as well as malignant thyroid disease. This will help to facilitate the long-term follow-up of these patients so that more comprehensive information regarding theoretical risks can be gathered. Whether the identified trend reflects changes in practice in Europe as a whole needs to be established.

\section{Declaration of interest}

The authors declare that there is no conflict of interest that could be perceived as prejudicing the impartiality of the research reported.

\section{Funding}

This research did not receive any specific grant from any funding agency in the public, commercial or not-for-profit sector.

\section{Author contribution statement}

$\mathrm{N}$ Turner and I Driver were involved in study design and contacted units, collected data, constructed the database and checked the manuscript. J A Salotti and M S Pearce provided advice during the analysis and helped prepare and check the manuscript. T Cheetham designed the study, undertook the analysis and wrote the manuscript.

\section{Acknowledgements}

The authors would like to thank all the Medical Physics departments that kindly took time to send us their local data.

\section{References}

1 Read CH, Tansey MJ \& Menda Y. A 36-year retrospective analysis of the efficacy and safety of radioactive iodine in treating young Graves' patients. Journal of Clinical Endocrinology and Metabolism 200489 4229-4233. (doi:10.1210/jc.2003-031223)

2 Rivkees SA \& Dinauer C. An optimal treatment for pediatric Graves' disease is radioiodine. Journal of Clinical Endocrinology and Metabolism 200792 797-800. (doi:10.1210/jc.2006-1239)

3 Léger J, Gelwane G, Kaguelidou F, Benmerad M, Alberti C \& the French Childhood Graves' Disease Study Group. Positive impact of long-term antithyroid drug treatment on the outcome of children with Graves' disease: National Long-Term Cohort Study. Journal of Clinical Endocrinology and Metabolism 201297 110-119. (doi:10.1210/jc.2011-1944)

4 Cheetham TD, Wraight EP, Hughes IA \& Barnes ND. Radioiodine treatment of Graves' disease in young people. Hormone Research 199849 255-259. (doi:10.1159/000023183)

5 Glinoer D, Hesch D, Lagasse R \& Laurberg P. The management of hyperthyroidism due to Graves' disease in Europe in 1986. Results of an international survey. Acta Endocrinologica Supplementum $19872853-23$.

6 Solomon B, Glinoer D, Lagasse R \& Wartofsky L. Current trends in the management of Graves' disease. Journal of Clinical Endocrinology and Metabolism $1990 \quad 70$ 1518-1524. (doi:10.1210/jcem-70-6-1518)

7 Vaidya B, Williams GR, Abraham P \& Pearce SH. Radioiodine treatment for benign thyroid disorders: results of a nationwide survey of UK endocrinologists. Clinical Endocrinology $2008 \mathbf{6 8}$ 814-820. (doi:10.1111/j.1365-2265.2007.03097.x)

8 Williamson S \& Greene S. Incidence of thyrotoxicosis in childhood: a national population based study in the UK and Ireland. Clinical Endocrinology 201072 358-363. (doi:10.1111/j.1365-2265. 2009.03717.x)

9 Wong GW \& Cheng PS. Increasing incidence of childhood Graves' disease in Hong Kong: a follow-up study. Clinical Endocrinology 200154 547-550. (doi:10.1046/j.1365-2265.2001.01252.x)

10 Nabhan ZM, Kreher NC \& Eugster EA. Hashitoxicosis in children: clinical features and natural history. Journal of Pediatrics 2005146 533-536. (doi:10.1016/j.jpeds.2004.10.070)

11 Cotterill SJ, Pearce MS \& Parker L. Thyroid cancer in children and young adults in the North of England. Is increasing incidence related to the Chernobyl accident? European Journal of Cancer 2001 37 1020-1026. (doi:10.1016/S0959-8049(00)00449-4)

12 Magnanti BL, Tevfik Dorak M, Parker L, Craft AW, James PW \& McNally RJQ. Geographical analysis of thyroid cancer in young people from northern England: evidence for a sustained excess in females in Cumbria. European Journal of Cancer 200945 1624-1629. (doi:10.1016/j.ejca.2008.12.024)

Received 21 June 2012

Revised version received 9 August 2012

Accepted 6 September 2012 